\title{
Illness Perceptions, Beliefs about Medication and Blood Pressure Control Among Hypertensive Egyptian Cohort
}

\author{
${ }^{1}$ Amany Mohammed AbdAllah, ${ }^{2}$ Hanaa A. Nofal, ${ }^{3}$ Mahmoud Ahmed Sharafeddin \\ ${ }^{1}$ Family Medicine Department, ${ }^{2}$ Public health and preventive medicine, ${ }^{3}$ Internal \\ Medicine Department, Faculty of Medicine, Zagazig University, Egypt.
}

\begin{abstract}
Objectives: To assess medication adherence, illness perception, beliefs about medications, to examine their association with blood pressure control among patients in Zagazig University hospital. Method: A cross-sectional study was held on 259 hypertensive patients attending Internal Medicine outpatient clinic, Zagazig University hospital. They underwent complete history taking, comprehensive clinical examination comprising assessing of their blood pressure. Then the patients completed Modified Morisky scale- 8 (MMS-8), brief illness perception (BIPQ) and belief about medication (BMQ) questionnaires. Results: About 55\% and 58\% reported poor blood pressure control and medication adherence respectively. There is statistically significant relation between blood pressure control and patients' sex, education, occupation, medication number, IPR causal domain, family history of hypertension-induced mortality, BIPR score, general overuse, specific necessity, specific concern, and adherence. There were significant relations between adherence and patients' sex, social class, marital status, education, occupation, duration, medications number, family history of hypertension-induced mortality, IPQ causal item, general overuse, specific concern, and necessity. Significant risk factors of both poor control and medication adherence included specific necessity $\leq 9$, general overuse $>15$ and using 3 to 4 drugs. Male, not working/unskilled increased risk of poor control. Not working/unskilled workers and skilled worker/free business, disease duration $>5$ years, perceiving lifestyle and hereditary as hypertension causes, having secondary education or higher were significant protectors from poor adherence. Conclusion: Belief about medications and illness perception were among the predictors of poor medication adherence and blood pressure control as well. Both can affect blood pressure control directly or indirectly via influencing adherence.
\end{abstract}

Keywords: perception, beliefs, adherence

Corrosponding author: Amany Mohammed AbdAllah E.mail: dr.amanymohammed@gmail.com

\section{Introduction}

Hypertension is a global public health issue. ${ }^{1}$ Its prevalence is expected to shoot by $30 \%$ during year $2025 .^{2}$ Poorly controlled hypertension represents a major concern in various countries. ${ }^{3}$

Hypertension is associated with bad effect on patients making them vulnerable to aggravated risk of heart disease, stroke and kidney disease. ${ }^{4}$ It will then impair productivity of patient and increase health expenditures so this disease has also an economic yield. ${ }^{4}$ In the general population younger than 60 years, pharmacologic treatment should be initiated when the systolic pressure is $140 \mathrm{~mm} \mathrm{Hg}$ or higher, or when the diastolic pressure is $90 \mathrm{~mm} \mathrm{Hg}$ or higher. The target systolic pressure in this population is less than $140 \mathrm{~mm} \mathrm{Hg}$, and the target diastolic pressure is less than $90 \mathrm{~mm} \mathrm{Hg}^{5}$

Medication adherence is the magnitude to which one's medication-taking behaviour agreed with that is mutually 
contracted upon with the prescribing physician. ${ }^{6}$ Suboptimal blood pressure control is strictly related to poor adherence to antihypertensive drugs and lifestyle changes. ${ }^{7-9}$

Correct reasonable awareness, positive perception, and attitudes about hypertension and its medication remain the corner stone for blood pressure control. $^{7}$

Patients' beliefs about illness are supposed to have a significant effect on medication adherence. ${ }^{10}$ Understanding barriers and determinants of adherence to antihypertensive medication may help physicians provide interventions that can increase patients' compliance. Such interventions can also improve patients' outcome. $^{11}$

This study aimed at assessing medication adherence, illness perception, beliefs about medications, examining their association with blood pressure control among hypertensive patients attending Internal Medicine outpatient clinic, Zagazig University hospital

\section{Method}

A cross sectional study was held through the period from October 2018 to September 2019 at Internal Medicine outpatient clinic in Zagazig University hospitals

Supposing that prevalence rate of nonadherence among adult Egyptian population $(71 \%)^{12}$ and attendance rate of patients with hypertension was $180 /$ month so the sample was calculated to be 235 patients. Ten $\%$ of calculated sample was added to compensate for potential drop out; hence a total of 259 patients were included. Sample size was calculated using open Epi program with power of study $80 \%$ and confidence level $95 \%$

Inclusion criteria: Adult patients (from 18 to 60 years old) of both sexes were included. All of them should be diagnosed with essential hypertension for at least one year ago.
Exclusion criteria: Existence of any of the following disorders: severe or acute hypertension, uncontrolled cardiovascular and cerebrovascular complications or associated comorbidities.

A systematic random sampling technique was adopted for selection of cases (as the patients were taken from outpatient clinic where there is no sample frame). As the average attendance is 6 patients /day and sample size of one to two patients/day was needed, so fourth patient starting from random number selected out of first six numbers was chosen in the sample. If patient was included before, it will be excluded and the next patient was used instead.

Case definition: In adult patients $(\leq 60$ years old), blood pressure control was defined as having systolic blood pressure $<140 \mathrm{mmHg}$ and diastolic blood pressure $<90 \mathrm{mmHg}$.

Study tools:

Socio-economic state (SES) was evaluated using modified version of the questionnaire of El Gilany et al., ${ }^{13}$ : Socio-demographic score $<50 \%$ (low), score $50 \%-<75 \%$ (middle) and score $\geq 75 \%$ (high) after modification.

Complete history taking: all patients underwent complete history taking including personal data, present, past and family history.

Morisky Medication Adherence Scale: The MMAS $-8^{\odot}$ is an eight items questionnaire is used to measure medication adherence. It is formed of seven Yes/No questions and the eighth question comprises a 5-point Likert scale. $^{14}$ Arabic version by Jamous et al., ${ }^{15}$ was used. That version had adequate internal consistency $(\alpha=$ $0.70) .{ }^{16}$ Total scores ranged from $0-8$ with a cut-off value for adequate adherence set at $\geq 6 .{ }^{14}$

The Brief Illness Perception Questionnaire (Brief IPQ): The Brief IPQ is used for measuring illness perceptions. It included nine items; 
Table (1a) Demographic and clinical characteristics of the studied patients

\begin{tabular}{|c|c|c|}
\hline Parameters & $\mathrm{N}=\mathbf{2 5 9}$ & $\%$ \\
\hline \multicolumn{3}{|l|}{ Age: } \\
\hline$\leq 35$ years & 144 & 55.6 \\
\hline$>35$ years & 115 & 44.4 \\
\hline Mean \pm SD & $36.32 \pm 10.22$ & \\
\hline Range & $20-59$ & \\
\hline \multicolumn{3}{|l|}{ Sex: } \\
\hline Male & 112 & 43.2 \\
\hline Female & 147 & 56.8 \\
\hline \multicolumn{3}{|l|}{ Marital status: } \\
\hline Single & 29 & 11.2 \\
\hline Married & 180 & 69.5 \\
\hline Divorced/widow & 50 & 19.3 \\
\hline \multicolumn{3}{|l|}{ SES: } \\
\hline Low & 193 & 74.5 \\
\hline Middle & 44 & 17 \\
\hline High & 22 & 8.5 \\
\hline \multicolumn{3}{|l|}{ Education: } \\
\hline Less than secondary & 140 & 54.1 \\
\hline Secondary and higher & 119 & 45.9 \\
\hline \multicolumn{3}{|l|}{ Occupation: } \\
\hline Not working and Unskilled & 139 & 53.7 \\
\hline Skilled/ Free trades, & 65 & 25.1 \\
\hline clerk and professional/semi & 55 & 21.2 \\
\hline \multicolumn{3}{|l|}{ Duration: } \\
\hline$\leq 5$ years & 160 & 54.1 \\
\hline$>5$ years & 99 & 45.9 \\
\hline \multicolumn{3}{|l|}{ Medication: } \\
\hline $1-2$ & 124 & 47.9 \\
\hline $3-4$ & 135 & 52.1 \\
\hline \multicolumn{3}{|l|}{ Drugs: } \\
\hline Diuretics & 159 & 61.4 \\
\hline ACEIs/ARBs & 148 & 57.1 \\
\hline $\mathrm{CCBs}$ & 49 & 18.9 \\
\hline Beta-blockers & 169 & 65.3 \\
\hline \multicolumn{3}{|l|}{ Causal effect: } \\
\hline Stress & 117 & 45.2 \\
\hline Hereditary & 71 & 27.4 \\
\hline Lifestyle & 71 & 27.4 \\
\hline \multicolumn{3}{|l|}{ Family history: } \\
\hline Irrelevant & 166 & 64.1 \\
\hline & 93 & 35.9 \\
\hline \multicolumn{3}{|l|}{ Family history of mortality: } \\
\hline Negative & 207 & 79.9 \\
\hline Positive & 52 & 20.1 \\
\hline
\end{tabular}

consequences, timeline, personal control, treatment control, identity, coherence, emotional representation and Illness concern. This mirrors a combination of emotional and cognitive representation. Each item is rated on a scale from 0 to 10 , with the global score fluctuating from 0 80. Item 9, causal one, probes the roots of hypertension by an open-ended question, by which patients enumerate three factors they thought to be the incriminated risk. Potentially, overall score can be calculated to uncover the degree to which the illness is alleged as threatening or benign. ${ }^{17}$ Arabic version of Saarti, et al. ${ }^{18}$ was used with Cronbach's alpha (0.717) and good internal consistency.
Table (1b) Demographic and clinical characteristics of the studied patients

\begin{tabular}{|c|c|c|}
\hline Parameters & $\mathrm{N}=259$ & $\%$ \\
\hline \multicolumn{3}{|l|}{ Brief IPR } \\
\hline$\leq 45$ & 138 & 53.3 \\
\hline$>45$ & 121 & 46.7 \\
\hline \multicolumn{3}{|l|}{ General overuse: } \\
\hline$\leq 15$ & 164 & 63.3 \\
\hline$>15$ & 95 & 36.7 \\
\hline \multicolumn{3}{|l|}{ General harm: } \\
\hline$\leq 15$ & 142 & 54.8 \\
\hline$>15$ & 117 & 45.2 \\
\hline \multicolumn{3}{|l|}{ Specific concern: } \\
\hline$\leq 21$ & 130 & 50.2 \\
\hline$>21$ & 129 & 49.8 \\
\hline \multicolumn{3}{|l|}{ Specific necessity: } \\
\hline$\leq 9$ & 143 & 55.2 \\
\hline$>9$ & 116 & 44.8 \\
\hline \multicolumn{3}{|l|}{ Adherence: } \\
\hline Poor & 97 & 25.9 \\
\hline Good & 162 & 74.1 \\
\hline \multicolumn{3}{|l|}{ Blood pressure control: } \\
\hline Poor & 143 & 55.2 \\
\hline Good & 116 & 44.8 \\
\hline 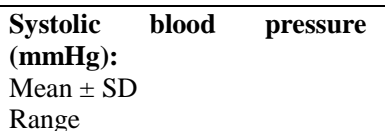 & \multicolumn{2}{|c|}{$\begin{array}{c}143.78 \pm 18.97 \\
120-170\end{array}$} \\
\hline $\begin{array}{lll}\begin{array}{l}\text { Diastolic } \\
(\mathbf{m m H g}):\end{array} & \text { blood } & \text { pressure } \\
\text { Mean } \pm \text { SD } & & \\
\text { Range } & & \end{array}$ & \multicolumn{2}{|c|}{$\begin{array}{c}88.98 \pm 7.43 \\
80-105\end{array}$} \\
\hline $\begin{array}{l}\text { ES Socioeconomic status, } \\
\text { onverting enzyme inhibitors/Angio } \\
\text { CB (calcium channel blockers }\end{array}$ & $\begin{array}{l}\text { ARBs } \quad(A n \\
\text { receptors }\end{array}$ & nsin \\
\hline
\end{tabular}

Belief about Medication Questionnaire (BMQ): It is an 18-item questionnaire which determines medication beliefs generally it includes two main domains; perception of medication in general (BMQ-General), as well as in specific chronic illnesses (BMQ -Specific). ${ }^{19}$

The BMQ-General encompasses 8 items which in turn are segmented into two sub-scales. The General-Harm sub-scale measures beliefs about how injurious the drugs are and the General-Overuse subscale discloses the thought of overprescription of medication by physicians. The items are recorded on a 5-point Likert scale with scores fluctuating from 4 to $20 .{ }^{19}$

The BMQ-Specific comprises 10 items which included two sub-scales. SpecificConcerns scale measures perceptions of the potentiality of adverse reactions the prescribed drug produces. The SpecificNecessity scale addresses the patients' belief about their need to adhere to drugs. ${ }^{19}$ 
Higher scores in the General-Harm and General-Overuse scales denote an overall negative perception of medication. High scores in the Specific-Concerns scale represent the conception that adverse reactions of using drugs on regular basis are potentially hazardous. Increasing the Specific-Necessity scale scores points to the patient's need to adhere to medication to maintain health. To calculate the score, reverse score items 3 , 4 , and 7 and add these to items 1, 2, 5, 6, and 8. A higher score reflects a more threatening view of the illness. Arabic version of Al-Noumani et al. ${ }^{7}$ was used with Cronback Alpha was 0.73.

Thorough clinical examination: Complete general examination with measuring of blood pressure using standard precautions according to JNC8 guidelines, measuring heart rate, respiratory rate and temperature. Local clinical examination was done with focusing on cardiac examination to detect potential complications.

Apparently complicated patients were excluded from the sample however they were managed by the internist.

A pilot study was applied on $10 \%$ of the sample size (26 patients) to check study feasibility, clarity of the questionnaires and calculate the time essential to fill in each questionnaire. Study tools were sufficiently clear and no adjustment was needed. Patients who were included in pilot study were excluded from the main field work.

Upon agreement to share in the study, informed oral consents were taken from the patients. All of them underwent compete history taking, thorough clinical examination. Blood pressure was measured using mercury sphygmomanometer while the patients were seated for 10 minutes after they were asked to evacuate their bladders. Then they filled in the questionnaires (it took approximately 35 minutes to complete the questionnaires) during waiting time for clinic consultation. For illiterate participants, the researchers read the question items word by word exactly as they appeared on the questionnaires. Responses were recorded. The questionnaires were collected immediately after being completed.

\section{Ethical Approval}

An official permission was obtained from Ethical committee of Faculty of Medicine, Zagazig University.

The required official approvals to accomplish the research were gotten from the head of the Internal Medicine department at Zagazig University Hospitals.

An informed oral consent was obtained from all study participants after ensuring confidentiality of their data.

\section{Statistical analysis}

Data analysis was accomplished using the software SPSS (Statistical Package for the Social Sciences) version 20. Quantitative data was represented using means and standard deviations. Categorical variables were designated using their absolute frequencies. Kolmogorov-Smirnov (distribution-type) and Levene (homogeneity of variances) tests were utilized to prove suppositions for use in parametric tests. For quantitative variables, independent samples t-test (t) was used to compare means of two groups while Mann Whitney U test was used for nonnormally distributed data. For categorical variables, Chi square $\left(\chi^{2}\right)$ and Fisher's exact tests were used to compare the studied groups. Binary backward Wald regression analysis was done to evaluate risk factors for poor blood pressure control and medication adherence. $\mathrm{P}$ value $<0.05$ was considered statistically significant, $\mathrm{p} \leq 0.001$ was considered as highly significant.

\section{Results}

Age of the studied patients ranged from 23 to 59 years with mean 40.83 years. Female constituted $56.8 \%$ of the studied patients and $69.5 \%$ were married. 
Table (2a) Association between poor blood pressure control and both demographic and disease related characteristics of the studied patients:

\begin{tabular}{|c|c|c|c|c|}
\hline \multirow[t]{2}{*}{ Parameters } & \multirow{2}{*}{$\begin{array}{l}\text { Total } \\
\mathbf{N}=259\end{array}$} & \multirow{2}{*}{$\begin{array}{c}\begin{array}{c}\text { Poorly controlled } \\
\text { Blood pressure }\end{array} \\
\mathrm{N}=143(\%) \\
\end{array}$} & \multirow[t]{2}{*}{$\mathbf{p}$} & \multirow[t]{2}{*}{ Odds ratio $(95 \% \mathrm{CI})$} \\
\hline & & & & \\
\hline \multicolumn{5}{|l|}{ Age: } \\
\hline$\leq 35$ years & 144 & $82(56.9)$ & & $1.17(0.72-1.92)$ \\
\hline$>35$ years & 115 & $61(53)$ & 0.53 & 1 (reference) \\
\hline \multicolumn{5}{|l|}{ Sex: } \\
\hline Male & 112 & $75(67)$ & & $2.35(1.41-3.92)^{*}$ \\
\hline Female & 147 & $86(46.3)$ & $<0.001 * *$ & 1 (reference) \\
\hline \multicolumn{5}{|l|}{ Marital status: } \\
\hline Single & 29 & $19(65.5)$ & & $1.74(0.77-3.95)$ \\
\hline Married & 180 & $94(52.2)$ & & 1 (reference) \\
\hline Divorced/widow & 50 & $30(60)$ & 0.224 & $1.37(0.73-2.59)$ \\
\hline \multicolumn{5}{|l|}{ SES: } \\
\hline Low & 193 & $108(56)$ & & $0.374(0.17-0.8)^{*}$ \\
\hline Middle & 44 & $34(77.3)$ & & 1 (reference) \\
\hline High & 22 & $1(4.5)$ & 0.351 & $0.014(0.001-0.12)^{*}$ \\
\hline \multicolumn{5}{|l|}{ Education: } \\
\hline Less than secondary & 140 & $105(75)$ & & $6.39(3.72-11.01)^{*}$ \\
\hline Secondary and higher & 119 & 38 (31.9) & $<0.001 * *$ & 1 (reference) \\
\hline \multicolumn{5}{|l|}{ Occupation: } \\
\hline Not working & 139 & $42(66.7)$ & & $5.19(2.61-10.3)^{*}$ \\
\hline Unskilled and skilled & 65 & $74(74.7)$ & & $7.67(4.07-14.48)^{*}$ \\
\hline Skilled & & & & \\
\hline Free trades, clerk and & 55 & $27(27.8)$ & & \\
\hline professional/semi & & & $<0.001 * *$ & 1 (reference) \\
\hline \multicolumn{5}{|l|}{ Duration: } \\
\hline$\leq 5$ years & 160 & $90(56.3)$ & & 1 (reference) \\
\hline$>5$ years & 99 & $53(53.5)$ & 0.669 & $0.9(0.54-1.48)$ \\
\hline \multicolumn{5}{|l|}{ Medication: } \\
\hline $1-2$ & 124 & $55(38.5)$ & & 1 (reference) \\
\hline $3-4$ & 135 & $88(61.5)$ & $0.001 * *$ & $2.35(1.42-3.88)^{*}$ \\
\hline \multicolumn{5}{|l|}{ Drugs: } \\
\hline Diuretics & 159 & $90(56.6)$ & 0.05 & $1.64(0.997-2.7)$ \\
\hline ACEIs/ARBs & 148 & $65(43.9)$ & $<0.001 * *$ & $0.18(0.1-0.29)^{*}$ \\
\hline $\mathrm{CCBs}$ & 49 & $19(38.8)$ & 0.376 & $0.74(0.37-1.45)$ \\
\hline Beta-blockers & 169 & $50(29.6)$ & $<0.001 * *$ & $0.02(0.1-0.06)^{*}$ \\
\hline \multicolumn{5}{|l|}{ Causal effect: } \\
\hline Stress & 117 & $62(53)$ & & 1 (reference) \\
\hline Hereditary & 71 & $52(73.2)$ & & $2.43(1.28-4.6)^{*}$ \\
\hline Lifestyle & 71 & $29(40.8)$ & 0.255 & $0.61(0.35-1.11)$ \\
\hline \multicolumn{5}{|l|}{ Family history: } \\
\hline Irrelevant & 166 & $90(62.9)$ & & $0.89(0.54-1.49)$ \\
\hline Relevant & 93 & $53(37.1)$ & 0.667 & 1 (reference) \\
\hline \multicolumn{5}{|l|}{$\begin{array}{l}\text { Family history of } \\
\text { mortality: }\end{array}$} \\
\hline Negative & 207 & $123(59.4)$ & & $2.34(1.26-4.37)^{*}$ \\
\hline Positive & 52 & $20(38.5)$ & $0.007 *$ & 1 (reference) \\
\hline
\end{tabular}


Table (2b) Association between poor blood pressure control and both demographic and disease related characteristics of the studied patients:

\begin{tabular}{|c|c|c|c|c|}
\hline \multirow[t]{2}{*}{ Parameters } & Total & $\begin{array}{c}\text { Poorly controlled Blood } \\
\text { pressure }\end{array}$ & \multirow[t]{2}{*}{$\mathbf{p}$} & \multirow[t]{2}{*}{ Odds ratio $(95 \% \mathrm{CI})$} \\
\hline & $\mathrm{N}=\mathbf{2 5 9}$ & $\mathrm{N}=143(\%)$ & & \\
\hline \multicolumn{5}{|l|}{ Brief IPR } \\
\hline$\leq 45$ & 138 & $94(68.1)$ & & $3.14(1.89-5.23)^{*}$ \\
\hline$>45$ & 121 & $49(40.5)$ & $<0.001 * *$ & 1 (reference) \\
\hline \multicolumn{5}{|l|}{ General overuse: } \\
\hline$\leq 15$ & 164 & $76(46.3)$ & & 1 (reference) \\
\hline$>15$ & 95 & $67(70.5)$ & $<0.001 * *$ & $2.77(1.62-4.74)^{*}$ \\
\hline \multicolumn{5}{|l|}{ General harm: } \\
\hline$\leq 15$ & 142 & $76(53.5)$ & & 1 (reference) \\
\hline$>15$ & 117 & $67(57.3)$ & 0.547 & $1.16(0.72-1.91)$ \\
\hline \multicolumn{5}{|l|}{ Specific concern: } \\
\hline$\leq 21$ & 130 & $53(40.8)$ & & 1 (reference) \\
\hline$>21$ & 129 & $90(69.8)$ & $<0.001 * *$ & $3.35(2.01-5.6)^{*}$ \\
\hline \multicolumn{5}{|l|}{ Specific necessity: } \\
\hline$\leq 9$ & 143 & $106(74.1)$ & & $6.12(3.56-10.51)^{*}$ \\
\hline$>9$ & 116 & $37(31.9)$ & $<0.001 * *$ & 1 (reference) \\
\hline \multicolumn{5}{|l|}{ Adherence: } \\
\hline Poor & 97 & 77 (79.4) & & $5.6(3.13-10.03)^{*}$ \\
\hline Good & 162 & $66(40.7)$ & $<0.001 * *$ & 1 (reference) \\
\hline
\end{tabular}

Concerning level of education; $54.1 \%$ received less than secondary education. About $54 \%$ of them were not working/unskilled workers and about three quarters of patients had low socioeconomic class (SES) (Table 1).

Systolic blood pressure ranged from 120 to $170 \mathrm{mmHg}$ while diastolic blood pressure lied within range of 80 to 105 mmHg. Patients who had $\mathrm{SBP}<140$ $\mathrm{mmHg}$ and $\mathrm{DBP}<80$ were considered controlled and represented $44.8 \%$. Patients had hypertension for 1 to 14 years. Patients reported that they received from 1 to 4 antihypertensive medications. About 61\%, 57\%, 19\% and $65 \%$ were on diuretics, Angiotensin converting enzyme inhibitors/Angiotensin receptors blockers (ACEI/ARBs), calcium channel blockers (CCB) and beta blockers respectively. On measuring medication adherence using MMS-8, score ranged from 0 to 8 with $57.9 \%$ were poor controlled. Regarding blood pressure control, about $55 \%$ had poor control (Table 1).
Concerning BMQ, means general overuse and harm subscales were 13.26 and 14.19 respectively. While specific concern and necessity subscales ranged from 5 to 25 each with means 18.48 and 10.74 respectively. Total score of the first 8 items of Brief IPR was 46.7 ranged from 18 to 74 . Regarding causal item, stress was ranked as the most important cause in $45.2 \%$ while each of hereditary and family history represented $27.4 \%$ each.

There is statistically significant relation between blood pressure control and each of patient sex, education, occupation, number of medication, use of ACEI or beta blockers, IPR causal domain, family history of mortality due to hypertension, total brief IPR score, general overuse, specific necessity, specific concern and adherence. There is non-significant relation between level of blood pressure control and either age group, marital status, SES, disease duration and general harm (Table 2).

On univariate analysis of those factors, male sex, receiving less than secondary 
Table (3) Logistic regression analysis of risk factors for poor blood pressure control:

\begin{tabular}{|c|c|c|c|c|c|}
\hline & & & $95 \%$ & & \\
\hline & $\mathbf{p}$ & AUK & Lower & Upper & $\mathbf{p}$ \\
\hline Causal factors (stress) ${ }^{*}$ & & & & & 0.536 \\
\hline Causal factors (Lifestyle) & 0.051 & 1.052 & 0.097 & 11.437 & 0.966 \\
\hline Causal factors (Hereditary) & 1.1 & 3.003 & 0.359 & 25.131 & 0.31 \\
\hline Male sex & 2.32 & 10.173 & 2.521 & 41.049 & $0.001 * *$ \\
\hline $\begin{array}{llll}\begin{array}{l}\text { Education } \\
\text { higher) }\end{array} & \text { (secondary school and } \\
\end{array}$ & -23.533 & 0.000 & 0.000 & & 0.995 \\
\hline Disease duration ( $>5$ years) & -27.176 & 0.000 & 0.000 & & 0.994 \\
\hline General over use score (>15) & 3.239 & 25.505 & 6.754 & 96.314 & $<0.001 * *$ \\
\hline Specific concern score $(>21)$ & 0.151 & 1.163 & 0.17 & 7.957 & 0.878 \\
\hline Specific necessity score $(<9)$ & 2.648 & 14.132 & 4.628 & 43.149 & $<0.001 *$ \\
\hline Number of medications (3 to 4) & 4.022 & 55.824 & 12.859 & 242.35 & $<0.001 *$ \\
\hline Brief IPR score $\leq 45$ & 1.441 & 4.225 & .724 & 24.661 & 0.109 \\
\hline Poor medication adherence & 1.059 & 2.883 & 0.968 & 8.586 & 0.057 \\
\hline Clerk, semi/professional $^{*}$ & & & & & $0.035^{*}$ \\
\hline Not working and unskilled v & 1.804 & 6.072 & 1.075 & 34.304 & $0.041^{*}$ \\
\hline Skilled workers and free business & 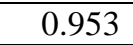 & 2.594 & 0.549 & 12.262 & \\
\hline
\end{tabular}

AOR adjusted odds ratio CI Confidence interval ${ }^{*} p<0.05$ is statistically significant ${ }^{* *} p \leq 0.001$ is statistically highly significant ${ }^{*}$ reference category

education, brief IPR $\leq 45$, specific necessity $\leq 9$ and poor medication adherence significantly increased risk of poor blood pressure control by 2.974 , $6.39, \quad 3.14, \quad 6.12$ and 5.6 folds respectively. Being not working/unskilled or skilled/free business, using from 3 to 4 drugs increased significantly risk of poor control by 5.19, 7.67 and 2.35 folds respectively. use of ACEI/ARBs or Beta blockers protected against poor blood pressure control (Table 2).

On doing binary backward Wald logistic regression analysis, not working and unskilled $(\mathrm{AOR}=6.072)$, skilled workers or free business (AOR=2.594), BMQ general overuse score $>21$ $(\mathrm{AOR}=25.505), \quad \mathrm{BMQ}$ specific concern $>15 \quad(\mathrm{AOR}=1.163), \quad \mathrm{BMQ}$ specific $\quad$ necessity $\leq 9 \quad(\mathrm{AOR}=14.132)$, number of medication $[3$ to 4$]$ (AOR=55.824), male sex (AOR=10.173), poor medication adherence $(\mathrm{AOR}=2.883)$, and brief $\mathrm{IPR} \leq 45$ (AOR=4.225) were independent risk factors for poor control (Table 3 ).

There were significant relations between adherence and sex, social class, marital status, education, occupation, duration, number of medications, use of diuretics, family history of hypertension-induced mortality, causal item of IPQ, general overuse, specific concern and specific necessity (Table 4). Male sex $(\mathrm{COR}=2.974)$, unskilled and skilled workers $(\mathrm{COR}=2.73)$, had less than secondary education $(\mathrm{COR}=8)$, negative family history of hypertension-induced mortality $\quad(\mathrm{COR}=2.05)$, perceiving hereditary $\quad(\mathrm{COR}=0.44)$, lifestyle as causes of hypertension (COR $=0.58)$, general overuse $>15 \quad(\mathrm{COR}=2.23)$, specific concern $>21(\mathrm{COR}=4.19)$ and specific necessity $\leq 9 \quad(\mathrm{COR}=5.6)$ were significant risk factor of poor medication adherence. Use of diuretics significantly increased risk of poor adherence by 2.13 folds (Table 4).

On doing binary backward logistic regression analysis, BMQ specific necessity $\leq 9(\mathrm{AOR}=2.599)$, BMQ general overuse score $(>15)(\mathrm{AOR}=4.741)$, using 3 to 4 drugs $(\mathrm{AOR}=2.721)$ were risk factors of poor medication adherence. Being not working/unskilled workers $(\mathrm{AOR}=0.111)$ and skilled worker/free business $\quad(\mathrm{AOR}=0.145), \quad$ disease duration $>5$ years $\quad(\mathrm{AOR}=0.085)$, perceiving lifestyle (AOR=0.176) and hereditary (AOR=0.148) as causes of hypertension, having secondary education or higher (AOR=0.012) were 
Table (4a) Association between poor medication adherence and both demographic and disease related characteristics of the studied patients:

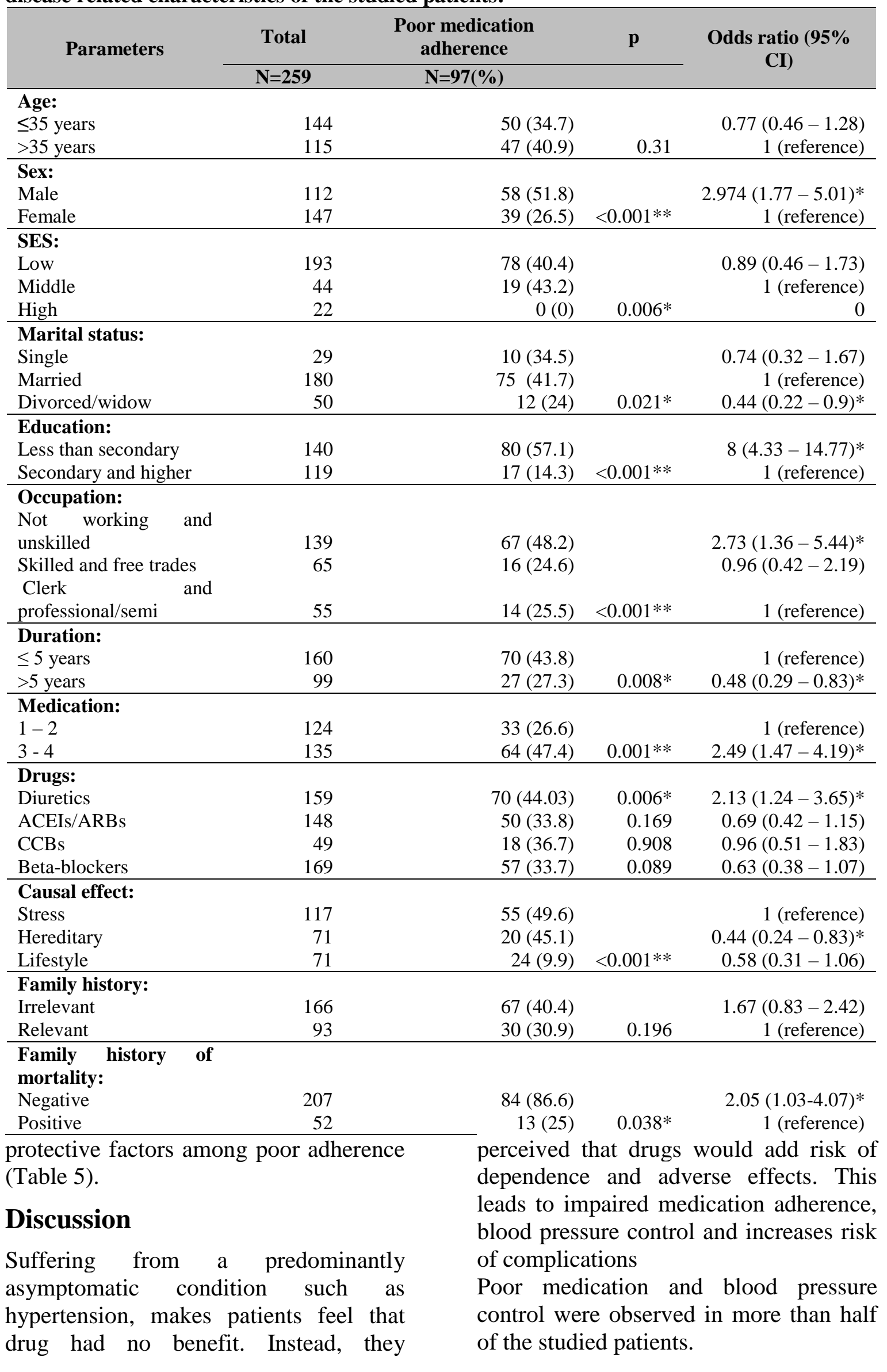


Table (4b) Association between poor medication adherence and both demographic and disease related characteristics of the studied patients:

\begin{tabular}{|c|c|c|c|c|}
\hline \multirow[t]{2}{*}{ Parameters } & Total & $\begin{array}{l}\text { Poor medication } \\
\text { adherence }\end{array}$ & $\mathbf{p}$ & \multirow{2}{*}{$\begin{array}{c}\text { Odds ratio }(95 \% \\
\text { CI) }\end{array}$} \\
\hline & \multirow{2}{*}{\multicolumn{3}{|c|}{$\mathrm{N}=97(\%)$}} & \\
\hline \multicolumn{2}{|l|}{ Brief IPR } & & & \\
\hline$\leq 45$ & 138 & $56(40.6)$ & & $1.33(0.8-2.21)$ \\
\hline$>45$ & 121 & $41(33.9)$ & 0.267 & 1 (reference) \\
\hline \multicolumn{5}{|l|}{ General overuse: } \\
\hline$\leq 15$ & 164 & $50(30.5)$ & & 1 (reference) \\
\hline$>15$ & 95 & $47(49.5)$ & $0.002 *$ & $2.23(1.32-3.76)^{*}$ \\
\hline \multicolumn{5}{|l|}{ General harm: } \\
\hline$\leq 15$ & 142 & 47() & & 1 (reference) \\
\hline$>15$ & 117 & $50(38.7)$ & 0.111 & $1.51(0.91-2.5)$ \\
\hline \multicolumn{5}{|l|}{ Specific concern: } \\
\hline$\leq 21$ & 130 & $28(21.5)$ & & 1 (reference) \\
\hline$>21$ & 129 & $69(53.5)$ & $<0.001 * *$ & $8.74(4.6-15.25)^{*}$ \\
\hline \multicolumn{5}{|l|}{ Specific necessity: } \\
\hline$\leq 9$ & 143 & $77(53.8)$ & & $5.6(3.13-10.01)^{*}$ \\
\hline$>9$ & 116 & $20(17.2)$ & $<0.001 * *$ & 1 (reference) \\
\hline
\end{tabular}

CI Confidence interval ${ }^{*} p<0.05$ is statistically significant ${ }^{* *} p \leq 0.001$ is statistically highly significant COR crude odds ratio ACEI/ARBs (Angiotensin converting enzyme inhibitors/Angiotensin receptors blockers), CCB (calcium channel blockers)

In a prior Ethiopian research by Muleta et al. $^{20}, 43.51 \%$ reported good blood pressure control. They also reported that patients' older $\geq 50$ years, female, disease duration, non-adherence and poorly controlled diabetes were significant predictors for uncontrolled hypertension.

In a survey in Cameron, $63.2 \%$ of patients had poor blood pressure control. Non-adherence was associated with poor blood pressure control. ${ }^{21}$

In prior study held in Saudi Arabia, 54\% of them were non-adherent to antihypertensive medications. Male sex, patients older than 65 years, and comorbid diabetes were risk factors of poor medication adherence. ${ }^{22}$

Non-adherence to antihypertensive drugs ranges from $45.2 \%$ to $66.7 \%$ in low- and middle-income countries. $^{2,23}$ Furthermore, only $6.2 \%$ of hypertensive patients were confirmed to have a high level of adherence in Saudi Arabia. ${ }^{24}$ In China, only $21.3-35.23 \%$ of patients showed good or optimal adherence to their antihypertensive therapy. ${ }^{25-26}$

Poor medication adherence was reported in in $58.6 \%$ in a previous study in Ghana. ${ }^{27}$ In a previous Egyptian study, non-adherence was prevalent among adult patients (29.03\%). ${ }^{12}$ Farahat et al. ${ }^{12}$, also reported that poor adherence was more prevalent among adult as compared to elderly patients. In That study showed female sex was associated with nonadherence in disharmony with the current study.

Shelley et al. ${ }^{28}$ denied role of medication number or income on blood pressure control yet they confirmed relation between male sex and poor control in disagreement with the current study where increasing number of drugs (from 3 to 4 increased risk by about 56 folds that may be attributed to poor adherence).

Male sex is considered a risk factor for poor medication adherence and hence, blood pressure control. Feeling that their disease is a burden that hinders work and necessitates drug use with increased expenditures can explain this finding. This, in turn, represents a big load on male patients who are supposed to be the active members in society and have the main financial responsibilities of their families.

Having positive family history of mortality due to hypertension raised concerns about importance of medication 
Table (5) Logistic regression analysis of risk factors for poor medication adherence:

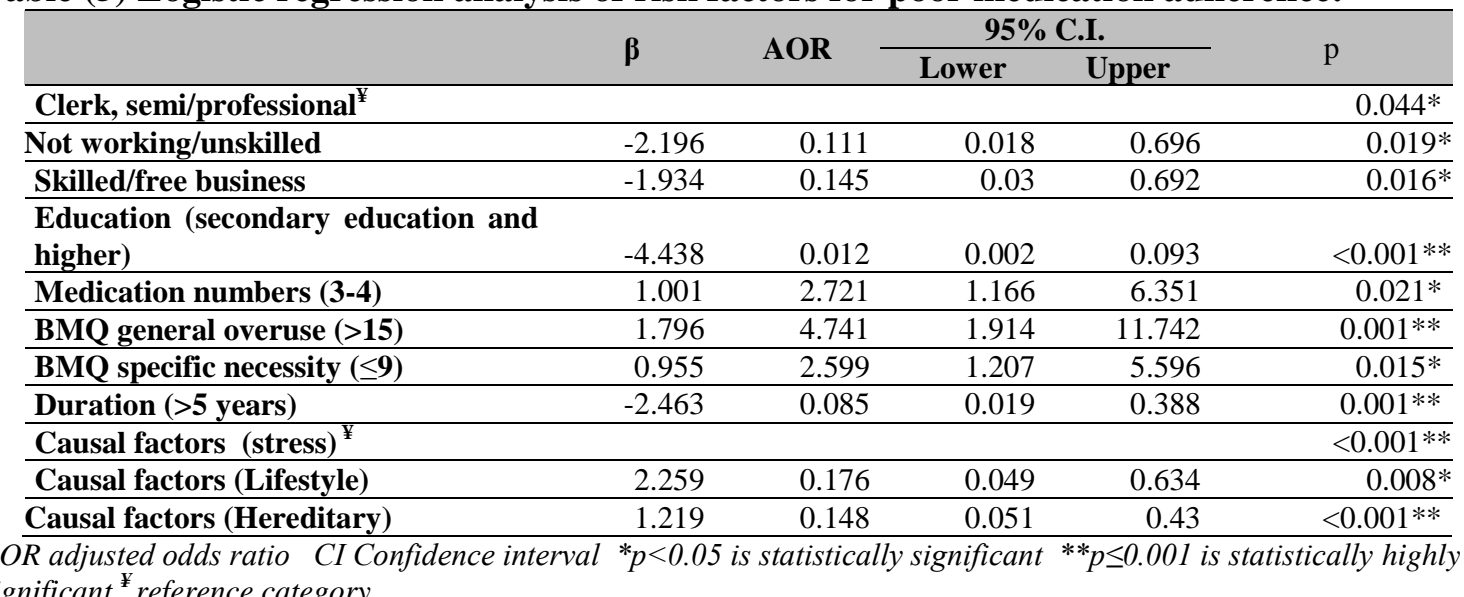

adherence and optimal blood pressure control as appeared in this research. Increased BIPQ scores denoted that hypertension is perceived as life threatening condition which is considered double edged weapon. However, in our patients, it was protective factor of both poor adherence and control. Using minimal number of drugs significantly protected against poor adherence and control. This can reassure patients that adverse effects will be less and decreases risk of forgetfulness of using drugs.

Regarding type of drug uses, both beta blockers and ACEI/ARBs protected against poor blood pressure control while diuretics increased risk of poor medication adherence and hence poor blood pressure control. Diuretics are known to be linked with many adverse effects as electrolyte imbalance and social embracement in the form of repeated micturition.

Perceiving lifestyle and hereditary as causes of hypertension increased risk of poor control as the patient felt that getting the disease is inevitable while perceiving it as a consequence of bad lifestyle made patients feel empowered. Also, lifestyle modifications are not so easy. Perception of need of lifestyle modification and further changes may appear as obstacles for poor control but not adherence. On the other hand, both protect against poor medication adherence.
Education and occupation had unpredictable effect on outcome measures. Increasing education level, and hence occupation is supposed to improve medication adherence via increasing awareness. Also, high education and working as professional or semiprofessional are also associated with high stress especially in type A personality which if increased medication adherence yet, it undermines blood pressure control. In the current study, in logistic regression analysis, occupation either not working/unskilled, skilled/free business protected against poor medication adherence. While both increased risk of poor blood pressure control. There are many confounders, including income, act as an obstacle facing medication adherence which neutralize protective effect of higher education and occupation

Previous, qualitative study revealed that perceiving hypertension as benign disease increased risk of poor control. ${ }^{24}$ In a previous research, non-significant association was found between blood pressure control and the BMQ- specificnecessity subscale in disagreement with our study. ${ }^{25}$

Poor medication adherence acts a significant risk factor for poor adherence which is axiomatic. Patients with poor adherence were found to be at 1.4 times more likely to have uncontrolled hypertension. $^{26}$ This agreed with the current study. 
Beliefs about medicines alone were found to be responsible for $22.4 \%$ of non-adherence to chronic drug therapy. ${ }^{27}$ In the same context, Jamous et al. ${ }^{28}$ reported a significant association between adherence and both specific necessity and specific concern.

Horne et al. ${ }^{19}$ concluded that higher adherence was associated with stronger perceptions of necessity of treatment $(\mathrm{OR}=1.742)$, and fewer concerns about treatment $(\mathrm{OR}=0.504)$.

In a previous study in Oman, less than half of patients had adequate adherence. In that study, there is significant negative correlation between perceived severity, overuse, and medication adherence. There was significant positive correlation between specific necessity and adherence. $^{7}$

Rajpura and Nayak ${ }^{10}$ conveyed that about two thirds of their patients were non-adherent. Perceptions about illness and beliefs about medication jointly played a significant role in the prediction of compliance.

A study in Nigeria has shown that there was statistically significant relationship between patients' beliefs about antihypertensives and adherence to treatment. Patients who were adherent had strong belief that their medicines are effective in protecting them from complications. ${ }^{34}$

Several factors associated with poor or non-adherence had also been identified in many studies. These include sociodemographic factors, such as sex, age, education level, occupational status, or even race $^{2,23}$; socio-economic status, ${ }^{23}$; and family history, number of prescribed drugs, comorbidity, and duration of hypertension as clinical disease-related factors. ${ }^{36-37}$ Psychosocial factors also impact medication adherence, including depressed mood, perceived disease severity, self-rated health, and selfefficacy. ${ }^{7,38}$ Awareness and patient literacy $^{32,39}$ were also found to be predictors of compliance.
Beliefs about medications play a fundamental role in adherence patterns. Higher levels in beliefs of drugs' harm and higher concerns about pharmacological hypertensive treatment were related to low adherence. Beliefs of necessity and overuse did not influence adherence levels in a prior study. ${ }^{40}$

Control of illness was the most significant predictor of a favorable outcome ${ }^{41}$ Patients who believed in their own ability to control illness and had strong confidence in management plan reported better medication adherence in many studies. ${ }^{10,16,42}$

Hsiao and colleagues ${ }^{43}$ reported that there is a negative association between patients' beliefs about their control of illnesses, emotional representation and medication adherence.

Illness perceptions are influenced by information that patients receive from health care professionals and the satisfaction with the information received. Once patients report symptoms after a diagnosis, inconsistency between symptom attributions of patients and health professionals may arise. Eventually, patients may adopt the perspective of professionals, but they will continue to try to understand their symptom. Experience based on personal perceptions, not the illness entity can create more barriers to adherence to therapeutic regimens. ${ }^{42}$ Therefore, it is important to assess patients' views about their illness, symptoms, treatments and also their satisfaction with information received prior to and during treatment.

Patients seemed more concerned about becoming drug dependent. Low adherence level is higher among patients with more concerns about medications. This throws shades on importance of identifying such fears and probing their hidden agenda when evolving a plan of care.

A negative association was reported between patients' beliefs about illness control, emotional representation, and 
medication adherence. This may be attributed to the fact that patients of this study had high numbers of symptoms and negative emotional responses towards their illness. ${ }^{38}$

Among significant findings within the current study that some factors which impaired blood pressure control were protective from poor adherence as causal item of BIPQ and occupation. This can be explained that adherence is not the sole factor that affects blood pressure control. In addition, medication adherence was subjective which may not reflect the precise patients' act.

This study had many strength points. Both adherence and blood pressure control were measured as adherence is not the sole factor that can predict control. Importance of patient perception of disease and medication were assessed in relation to both adherence and illness control. To our knowledge, no other study in Egypt highlighted these points. This acts as a ground study to develop programs targeting perception and medication beliefs to empower patients and optimize blood pressure control. This will benefit patient, family, and the whole community. Addressing patient hidden agenda is an inevitable item in management

\section{Conclusion}

Belief about medications and degree of illness perception were among the predictors of poor medication adherence and blood pressure control as well. Both can affect blood pressure control directly or indirectly via influencing adherence. Poor medication adherence posed a significant risk for poor control of hypertension

Hence; assessment of medication beliefs and illness perception are important for success of management strategies. Health care providers should address the patient's beliefs about medications in the hope of improving medication adherence and patients' outcome.

Limitation of the study: Being cross sectional in nature, utilizing subjective tools for measuring adherence, illness perception and belies about medications with possible recall bias, being single center study on relatively small number of patients were the most significant boundaries.

\section{References}

1. Irazola V. E., Gutierrez L., Bloomfield G., Carrillo-Larco R. M., Dorairaj P., Gaziano T., et al. (2016). Hypertension prevalence, awareness, treatment, and control in selected LMIC communities: results from the NHLBI/UHG Network of Centers of Excellence for Chronic Diseases. Glob. Heart 11 (1), 47-59.

2. Abegaz T. M., Shehab A., Gebreyohannes E. A., Bhagavathula A. S., Elnour A. A. (2017). Nonadherence to antihypertensive drugs: A systematic review and meta-analysis. Medicine (Baltimore) 96 (4), e5641.

3. Ofili M. I., Ncama B. P., Sartorius B. (2015). Hypertension in rural communities in Delta State, Nigeria: prevalence, risk factors and barriers to health care. Afr. J. Prim. Health Care Fam. Med. 7 (1), 1-7. 10.4102/phcfm.v7i1.875

4. Sabaté E. Adherence to long-term therapies: evidence for action. Geneva, Switzerland: World Health Organization 2003. Available on https://http://www.who.int/chornic_condition s/en/adherence_report.pdf

5. Armstrong C; Joint National Committee. JNC 8 Guidelines for the Management of Hypertension in Adults. Am Fam Physician. 2014 Oct 1;90(7):503-504.

6. James PA Oparil S Carter BL. evidencebased guideline for the management of high blood pressure in adults: report from the panel members appointed to the Eighth Joint National Committee (JNC 8). JAMA 2014; 311: 507-520

7. Al-Noumani H, Wu JR, Debra Barksdale, Esra Alkhasawneh, George Knafl, Gwen Sherwood. Relationship Between Medication Adherence and Health Beliefs Among Patients with Hypertension in Oman. Pilot 
study. Sultan Qaboos University Med J, 2017, Vol. 17, Iss. 3, pp. e329-333, Epub.

8. Beune E., Nieuwkerk P., Stronks K., Meeks K., Schulze M. B., Mockenhaupt F. $\mathrm{P}$. , et al. Medication non-adherence and blood pressure control among hypertensive migrant and non-migrant populations of subSaharan African origin: the RODAM study. J. Hum. Hypertens 2019. 33 (2), 131148. 10.1038/s41371-018-0120-8

9. Sarfo F. S., Mobula L. M., Burnham G., Ansong D., Plange-Rhule J., Sarfo-Kantanka O., et al. Factors associated with uncontrolled blood pressure among Ghanaians: evidence from a multicenter hospital-based study. PLoS One 2018, 13 (3), e0193494.

10.1371/journal.pone.0193494

10.Rajpura JR, Nayak R. Role of illness perceptions and medication beliefs on medication compliance of elderly hypertensive cohorts. J Pharm Pract. 2014 Feb;27(1):19-24.

11.Krousel-Wood MA, Muntner P, Islam T, Morisky DE, Webber LS. Barriers to and determinants of medication adherence in hypertension management: perspective of the cohort study of medication adherence among older adults. Med Clin North Am 2009; 93 :753-769.

12.Farahat TM, Shaheen HM, Khalil NA, Hegazy N.N., Barakat AM. Comparative study between adult and elderly patients as regards adherence to antihypertensive medication. 2016. Menoufia Med J 29:121125

13.El-Gilany A, El-Wehady A, and ElWasify M. Updating and validation of the socioeconomic status scale for health research in Egypt. East Mediterr Health J 2012; 18(9):962-8.

14.Morisky DE, Ang A, Krousel-Wood M, Ward HJ. Predictive validity of a medication adherence measure in an outpatient setting. $\mathbf{J}$ Clin Hypertens (Greenwich). 2008 May;10(5):348-54.

15.Jamous RM, Sweileh WM, Abu-Taha AS, Sawalha AF, Zyoud SH, Morisky DE. Adherence and satisfaction with oral hypoglycemic medications: a pilot study in Palestine. Int J Clin Pharm. 2011 Dec;33(6):942-8.

16. Ashur ST, Shamsuddin IK,. Shah SA, Bosseri S. and $\backslash$ Morisky DE: Reliability and known-group validity of the Arabic version of the 8-item Morisky Medication Adherence Scale among type 2 diabetes mellitus patients. EMHJ • Vol. 21 No. $10 \cdot 201.722-$ 728.

17.Broadbent E, Petrie KJ, Main J, Weinman $\mathrm{J}$. The brief illness perception questionnaire. J Psychosom Res. 2006; 60(6):631-637

18. Saarti S, Hajj A, Karam L, et al. Association between adherence, treatment satisfaction and illness perception in hypertensive patients. J Hum Hypertens. 2016;30(5):341-345..

19.Horne R, Chapman SC, Parham R, Freemantle N, Forbes A, Cooper V. Understanding patients' adherence-related beliefs about medicines prescribed for longterm conditions: A meta-analytic review of the necessity-concerns framework. PloS One 2013:8;e80633.

20.Muleta, S., Melaku, T., Chelkeba, L. et al. Blood pressure control and its determinants among diabetes mellitus comorbid hypertensive patients at Jimma University medical center, South West Ethiopia. Clin Hypertens 23, 29 (2017).

21.Menanga, A., Edie, S., Nkoke, C., Boombhi, J., Musa, A., Mfeukeu, L., \& Kingue, S. (2016). Factors associated with blood pressure control amongst adults with hypertension in Yaounde, Cameroon: a cross-sectional study. Cardiovascular Diagnosis And Therapy, 6(5), 439-445.

22. Khayyat SM, Khayyat SMS, Hyat Alhazmi RS, Mohamed MMA, Abdul Hadi M (2017) Predictors of Medication Adherence and Blood Pressure Control among Saudi Hypertensive Patients Attending Primary Care Clinics: A CrossSectional Study. PLoS ONE 12(10): e0171255.

23.Nielsen J., Shrestha A. D., Neupane D., Kallestrup P.: Non-adherence to antihypertensive medication in low- and middleincome countries: a systematic review and meta-analysis of 92443 subjects. J. Hum. Hypertens 2017. 31 (1), 14-21.

24.Fatani F. N., Alsobaei R. M., Alobodi N. S., Alshehri Z. H., Alrajih H. A., Fallatah A. A., et al. (2019). Poor compliance to antihypertensive drugs among patients in Saudi Arabia. Indo Am. J. Pharm. Sci. 6 (2), 37523758.

25.Hou Y. Y., Zhang D. D., Gu J., Xue F., Sun Y., Wu Q., et al. (2016). The association between self-perceptions of aging and 
antihypertensive medication adherence in older Chinese adults. Aging Clin. Exp. Res. 28 (6), 1113-1120.

26.Pan J. J., Lei T., Hu B., Li Q. Postdischarge evaluation of medication adherence and knowledge of hypertension among hypertensive stroke patients in northwestern China. Patient Prefer. Adherence 2017 (11), 1915-1922.

27. Obirikorang Y, Obirikorang C, Acheampong E, Anto EO, Gyamfi D, Segbefia SP, Boateng MO, Dapilla DP,et al: Predictors of Noncompliance to Antihypertensive Therapy among Hypertensive Patients Ghana: Application of Health Belief Model. International Journal of Hypertension2018, vol 2018; 1-9

28. Shelley D, Tuo-Yen Tseng, Howard Andrews, Joseph Ravenell, Daren Wu, Pamela Ferrari, Asaf Cohen, Mari Millery, Helene Kopal, Predictors of Blood Pressure Control Among Hypertensives in Community Health Centers, American Journal of Hypertension, Volume 24, Issue 12, December 2011, Pages 1318-1323).

29.R. Rahmawati and B. Bajorek, "Understanding untreated hypertension from patients' point of view: A qualitative study in rural Yogyakarta province, Indonesia," Chronic Illness, vol. 14, no. 3, pp. 228-240, 2017

30.Tiffe T, Caroline Morbach, Viktoria Rücker, et al., "Impact of Patient Beliefs on Blood Pressure Control in the General Population: Findings from the PopulationBased STAAB Cohort Study," International Journal of Hypertension, vol. 2019, Article ID 9385397, 7 pages, 2019].

31. Xue J., Conwell Y., Tang W., Bogner H. R., Li Y., Jiang Y., et al. (. Treatment adherence as a mediator of blood pressure control in Chinese older adults with depression. Int. J. Geriatr. Psychiatry2019. 34 (3), 432-438.

32.

33.Phatak HM, Thomas J 3rd. Relationships between beliefs about medications and nonadherence to prescribed chronic medications. Ann Pharmacother. 2006 Oct;40(10):1737-42.

34.Jamous RM, Sweileh WM, El-Deen Abu Taha AS, Zyoud SH. Beliefs about medicines and self-reported adherence among patients with chronic illness: A study in Palestine. J Fam Med Primary Care 2014;3:224-9

35.Nielsen J., Shrestha A. D., Neupane D., Kallestrup P.. Non-adherence to antihypertensive medication in low- and middleincome countries: a systematic review and meta-analysis of 92443 subjects. J. Hum. Hypertens 2017. 31 (1), 14-21.

36.Fatani F. N., Alsobaei R. M., Alobodi N. S., Alshehri Z. H., Alrajih H. A., Fallatah A. A., et al. (2019). Poor compliance to antihypertensive drugs among patients in Saudi Arabia. Indo Am. J. Pharm. Sci. 6 (2), 37523758.

37.Hou Y. Y., Zhang D. D., Gu J., Xue F., Sun Y., Wu Q., et al. (2016). The association between self-perceptions of aging and antihypertensive medication adherence in older Chinese adults. Aging Clin. Exp. Res. 28 (6), 1113-1120.

38.Pan J. J., Lei T., Hu B., Li Q. Postdischarge evaluation of medication adherence and knowledge of hypertension among hypertensive stroke patients in northwestern China. Patient Prefer. Adherence 2017 (11), 1915-1922.

39. Obirikorang Y, Obirikorang C, Acheampong E, Anto EO, Gyamfi D, Segbefia SP, Boateng MO, Dapilla DP,et al: Predictors of Noncompliance to Antihypertensive Therapy among Hypertensive Patients Ghana: Application of Health Belief Model. International Journal of Hypertension2018, vol 2018; 1-9

40.Labaran, K. S., Mohammed, M., Sa'eed, S. B., Wada, A.S. and Mustapha, S. relationship between patients' beliefs about their antihypertensive and adherence in secondary hospital in northern Nigeria. Bayero Journal of Pure and Applied Sciences 2017: 10(1): 276 - 279

41.Nurhussein L. K., Debesai M., Preeth J. S. (2018). Assessment of adherence and its contributing factors among hypertension patients in Eritrea. Lat. Am. J. Pharm. 37 (7), 1448-1456.

42.Choi H. Y., Oh I. J., Lee J. A., Lim J., Kim Y. S., Jeon T. H., et al. (2018). Factors affecting adherence to antihypertensive medication. Korean J. Fam. Med. 39 (6), 325-332.

43.Williams L. G., Peacock E., Joyce C., Bazzano L. A., Sarpong D., Whelton P. K., et al. (2018). Risk factors for low pharmacy refill adherence among older hypertensive 
men and women by race. Am. J. Med. Sci. 356 (5), 464-475.

44.Asgari M. R., Bouraghi H., Mohammadpour A., Haghighat M., Ghadiri R., (2019). The role of psychosocial determinants in predicting adherence to treatment in patient with hypertension. Interv. Med. Appl. Sci. 11 (1), 8-16.

45. Shirindi M. L., Makhubele J. C., Fraeyman J. (2016). Barriers to medication adherence among women living in rural areas suffering from hypertension: The Case of Dikgale-Communities. Stud. EthnoMed. 10 (1), 76-84.

46.Fernandez-Arias $M$, Acuna-Villaorduna A, Miranda JJ, Diez-Canseco F, Malaga G (2014) Adherence to Pharmacotherapy and
Medication-Related Beliefs in Patients with Hypertension in Lima, Peru. PLoS ONE 9(12): e112875.

47.Chen S, Tsai J, Chou K. Illness perceptions and adherence to therapeutic regimens among patients with hypertension: a structural modeling approach. Int $J$ Nurs Stud. 2011;48(2):235-245.

48.Chen S, Tsai J, Lee W-L. The impact of illness perception on adherence to therapeutic regimens of patients with hypertension in Taiwan. J Clin Nurs. 2009;18(15):2234-2244.

49.Hsiao C-Y, Chang C, Chen C-D. An investigation on illness perception and adherence among hypertensive patients. Kaohsiung $J$ Med Sci. 2012;28(8):442-447. 